\title{
HISTÓRIA E MEMÓRIA: POSSIBILIDADES DE AMPLIAÇÃO DO CONHECIMENTO NO ENSINO DE HISTÓRIA POR MEIO DE IMAGENS
}

\section{HISTORY AND MEMORY: POSSIBILITIES OF EXPANDING KNOWLEDGE IN HISTORY TEACHING THROUGH IMAGES}

\author{
Paulo Augusto Tamanini ${ }^{1}$, Ana Meyre de Morais $^{2}$
}

Submetido em: 29/07/2021

Aprovado em: 04/09/2021 e28616

https://doi.org/10.47820/recima21.v2i8.616

\begin{abstract}
RESUMO
A proposta apresenta algumas provocações feitas sobre o uso de imagem no ensino de história. Tendo como questão motivadora atentar para a importância de encontrar na escola um momento para se discutir sobre a sua própria história. Objetivando refletir sobre o poder da imagem enquanto ferramenta pedagógica no ensino de História que faz professores e alunos interagirem em sala de aula. O percurso metodológico consistiu primeiramente na busca de referenciais teóricos e fotografias que remontam a época de suas construções na sociedade. Buscamos ainda apresentar ambas as fotografias a exfuncionárias das respectivas escolas para observar como a imagem desperta as lembranças daqueles que fizeram parte do contexto da época. Servimo-nos dos seguintes aportes teóricos: Fonseca (2009), Macedo (2017), Fernandes (1995), Santos Júnior (1999), Morais (2007) e outros. No primeiro momento tratamos sobre a questão do interesse pelo passado, quando se privilegia um determinado recorte temporal. Enquanto que no segundo momento tratamos da questão de se dar visibilidade às imagens porque nelas se encontram guardadas parte de uma história. O resultado demonstrou que as imagens se mostram eficientes, com potencial para privilegiar a ampliação do conhecimento sobre determinado contexto.
\end{abstract}

PALAVRAS-CHAVE: Imagem. Ensino de História. História.

\begin{abstract}
The proposal presents some provocations made about the use of image in the teaching of history. Having as motivating question to pay attention to the importance of finding a time at school to discuss your own history. Aiming to reflect on the power of the image as a pedagogical tool in the teaching of History that makes teachers and students interact in the classroom. The methodological path consisted primarily of searching for theoretical references and photographs that go back to the time of their construction in society. We also seek to present both photographs to former employees of the respective schools to observe how the image awakens the memories of those who were part of the context of the time. We use the following theoretical contributions: Fonseca (2009), Macedo (2017), Fernandes (1995), Santos Júnior (1999), Morais (2007) and others. At first, we deal with the issue of interest in the past, when a particular time frame is privileged. While in the second moment we deal with the issue of giving visibility to the images because part of a story is kept in them. The result showed that the images prove to be efficient, with the potential to privilege the expansion of knowledge about a certain context.
\end{abstract}

KEYWORDS: Image. History teaching. History.

\footnotetext{
1 Pós-Doutor em História pelo PNPD/CAPES/UFPR. Doutor em História. Professor do Programa de Pós-Graduação em Ensino (UERN)

2 Mestre em Ensino pela Universidade Federal do Semiárido (UFERSA)

RECIMA21 - Ciências Exatas e da Terra, Sociais, da Saúde, Humanas e Engenharia/Tecnologia
} 


\section{RECIMA21 - REVISTA CIENTÍFICA MULTIDISCIPLINAR ISSN 2675-6218}

HISTÓRIA E MEMÓRIA: POSSIBILIDADES DE AMPLIAÇÃO DO CONHECIMENTO NO ENSINO DE HISTÓRIA POR MEIO DE IMAGENS Paulo Augusto Tamanini, Ana Meyre de Morais

\section{INTRODUÇÃO}

Onde se encontram os interessados pela riqueza da História? Esse questionamento se faz pertinente quando se tem em mente a pretensão de discutir sobre possibilidades de ampliação de conhecimento no Ensino de História, e ainda que nelas seja possível despertar o pensar sobre as riquezas das experiências pedagógicas que podem ser vivenciadas com imagens na sala de aula. A prática de transformações e dinamizações para o Ensino de História instiga professores e alunos em qualquer espaço escolar, que ao se depararem com tamanha riqueza de conhecimentos sentem-se seduzidos pela História, tanto no diz respeito ao ensino, como à pesquisa.

$\mathrm{Na}$ escola, o processo de ensino e aprendizagem se inicia e os processos de metodologias e de ensino vão ganhando novas formas, ampliam-se os diálogos entre professores e alunos, advêm pesquisas, trabalhos em grupo, debates e etc. São dinâmicas usuais que fazem desse espaço um ambiente de aprendizagem, onde o currículo escolar poderá ganhar vida. É com práticas variadas que o tipo de aula se define estimulante ou entedia. O que se deve ter em mente é que ações pedagógicas sejam pensadas de forma estruturadas para estimular a visão crítica dos alunos, pois com redescobertas passamos a nos conhecer, percebemo-nos como sujeitos produtores de conhecimento, de histórias. E para isso, deve existir um espaço na escola para que os alunos conheçam a versão mais aproximada de sua localidade, de sua escola.

Sendo assim, foi com base nessa ideia que propomos que a discussão seja iniciada por imagens, porque através delas uma nova reflexão é possível. Ao nos dispormos a fazer busca de informações sobre determinado tempo a partir de uma simples imagem, abre-se espaço e momento oportunos para se ouvir os ecos de uma história que é única. A história de uma localidade facilmente pode ser encontrada, isso porque o tipo de conhecimento a ser requerido diferencia-se daquele de nível mais elevado, oferece ao professor/historiador resultados rápidos das ideias sobre muitos momentos históricos de uma comunidade. Mas aí, qual seria a razão de visitar o passado para conhecer a história de um determinado munícipio? É nessa história que encontramos o início de tantas outras histórias, e a das escolas de uma cidade não fica de fora. Nem tão pouco poderia, porque existe o favorecimento de construção da identidade de seus alunos como seres históricos, cidadãos que partilham memórias. Logo, não se pode pensar em desenvolvimento para um país sem antes requerer um conhecimento sólido da própria história e ainda uma melhor compreensão da realidade em que se estar inserido.

A proposta deste artigo, com a discussão a partir de imagens, atenta para o poder da imagem enquanto ferramenta pedagógica no Ensino de História que faz professores e alunos interagirem em sala de aula. Assim, emerge a provocação para a história das escolas da comunidade, cujo percurso metodológico consistiu primeiramente na busca de referenciais teóricos, posteriormente em fotografias que remontam à época de construção de duas escolas do município de Baraúna-RN. O critério de escolha das fotografias se justifica pelo fato de se tratar das duas maiores escolas do referido município: uma da rede estadual e a outra da esfera municipal. 


\section{RECIMA21 - REVISTA CIENTÍFICA MULTIDISCIPLINAR ISSN 2675-6218}

HISTÓRIA E MEMÓRIA: POSSIBILIDADES DE AMPLIAÇÃO DO CONHECIMENTO NO ENSINO DE HISTÓRIA POR MEIO DE IMAGENS Paulo Augusto Tamanini, Ana Meyre de Morais

Duas fotografias das escolas foram mostradas a duas ex-funcionárias das escolas a fim de despertar lembranças daqueles que fizeram parte do contexto da época. No primeiro momento, tratamos sobre a questão do interesse pelo passado quando se privilegia um determinado recorte temporal. Depois, tratamos da questão em dar visibilidade às imagens, porque nelas se encontram guardadas parte de uma história.

\section{O INTERESSE PELO PASSADO}

Estudar o passado para compreender o presente pode ser uma resposta comum a ser dada a estudantes quando eles se veem diante de questionamentos sobre as razões de estudarmos a História. Por repetidas vezes, esse tipo de inquietação se apresenta em sala de aula e movimenta alunos e professor. A verdade é que esse tipo de confronto acontece e nem sempre as respostas dadas se mostram convincentes para aqueles que estudam os diferentes períodos históricos ao longo do ano letivo. No entanto, mesmo que tal resposta não os satisfaçam é por meio da História que podemos compreender a sociedade em que estamos inseridos. Barros (2006, p. 461) enfatiza que, "o que ela estuda na verdade são as ações e transformações humanas (ou permanências) que se desenvolvem ou se estabelecem em um determinado período de tempo, mais longo ou mais curto". Sendo assim, é importante que haja um alinhamento entre a sociedade e a História como disciplina.

A sociedade tem seus objetivos e a História como disciplina escolar precisa que seu currículo esteja articulado com eles para que as transformações possam ocorrer. E como campo de conhecimento, suas concepções sofrem também mudanças, conforme o significado que a ela lhes é atribuído, haja vista que são diversos devido aos interesses de cada época.

É importante destacar que no campo das Ciências Humanas, em meados do século XX, a História se expandiu, sendo redefinida de forma progressiva com novos objetos para serem explorados, assenhorando-se do Tempo Presente, por exemplo, o que incluía temporalidades que cabiam ao Historiador estudá-las. Com os domínios historiográficos expandidos foi possível aos historiadores compreender que se fazia necessário energizar a prática da interdisciplinaridade com as demais áreas do saber que, por conseguinte, vieram proporcionar novas chances de práticas e investigações.

Essa prática interdisciplinar que envolve os estudos historiográficos com outros saberes apresenta a possibilidade de diálogos com as mais variadas áreas do conhecimento. A título de exemplo, podemos dizer que a Geografia além de estudar o espaço físico o faz com outros tipos de espaço que envolve a História. Sua extensão alcança variadas áreas do saber que colaboram para que de fato exista um diálogo fortalecido, compromissado com o campo histórico e escolar.

Para iniciar um diálogo é preciso um ponto inicial em sala de aula para a discussão do passado. Sem que seja algo aleatório, mas a partir de planejamento. A proposta para visitar o passado poderá ser de forma dinâmica e enriquecedora a ponto de mostrar que nessas visitas o passado poderá despertar interesse nos estudantes. 


\title{
RECIMA21 - REVISTA CIENTÍFICA MULTIDISCIPLINAR ISSN 2675-6218
}

HISTÓRIA E MEMÓRIA: POSSIBILIDADES DE AMPLIAÇÃO DO CONHECIMENTO NO ENSINO DE HISTÓRIA POR MEIO DE IMAGENS Paulo Augusto Tamanini, Ana Meyre de Morais

Nesse sentido, como ponto de partida, lançamos a questão sobre o que possivelmente possa representar a História. Os saberes históricos são de fato importantes? A medida em que as abordagens sobre a área de História forem sendo feitas, o mais provável é que nos deparemos com desafios em detrimento de sua amplitude. Na sala de aula, o conhecimento histórico deve não só aproximar os discentes, mas estimular o interesse pela pesquisa no campo escolar, aproximando-os com as histórias de suas realidades, partindo de fontes históricas imagéticas da própria escola, por exemplo. E por meio dessas imagens está o desenvolvimento de da criticidade, tornando possível a redescoberta de novas maneira de sentir-se cidadão, além de se perceber como sujeito produtor de histórias, "[...] as imagens como os textos para a História têm seu papel (MORAIS e TAMANINI, 2020, p.17) ".

Atentar para a importância que a imagem fotográfica possui é procurar entender que ela possui um propósito a ser alcançado. Ela deve ser útil, não basta apenas visualizá-la, é preciso interpretá-la, senti-la para que se concretizem essa redescoberta de se perceber enquanto membro integrante de uma sociedade. Como diz Martins (2008, p. 23), "a fotografia é inútil se não tem sentido para determinada pessoa ou determinado público". Sendo assim, as imagens fotográficas do contexto de criação da escola haverão de ter sentido para os alunos.

Muitos familiares de alunos fizeram parte do momento de construção de história, mas esse momento vivenciado diz respeito à uma realidade específica, que não foi vivido pelas sociedades por um todo. As experiências humanas vivenciadas são distintas e o que acontece é que nos livros didáticos os conhecimentos históricos se encontram previamente organizados, situados no tempo conforme os marcos que definiram início e término. Mas a verdade é que fatos por si mesmos não constituem a História. Segundo Fagundes e Andrade (2017, p. 25) explicam:

\begin{abstract}
A História constitui um conhecimento acerca das experiências humanas em sua relação com as transformações pelas quais passam diferentes sociedades. Mas ela não se constitui apenas em um conjunto de lembranças, pois isso seria memória. A História é mais que isso. Ela é filha da memória e consiste num campo de produção de conhecimento sobre o passado, a partir das problemáticas/questões do presente e dos vestígios que chegam até o momento em que vive o historiador.
\end{abstract}

O historiador, quando se dispõe a se aprofundar num determinado fato, ele considera que existe um público que poderá se beneficiar de seus estudos. Os conhecimentos produzidos são baseados nos vestígios do passado que têm as ações humanas como questão principal.

Então, se vivemos num tempo em que existe um entendimento unânime de que tudo possui historicidade, que se debruçar sobre um determinado fato é atribui-Ihe importância, a escolha do objeto de pesquisa aqui não foi aleatória, mas consciente de que o passado tem sua relevância e deve ser estudado. Apresentar possibilidades de criações de novas práticas e provocações para a melhoria do Ensino de História por meio de imagens, de modo que seja possível o professor interagir e problematizar as imagens para que novos conhecimentos sejam produzidos, é um desafio. Mas que certamente o levantamento dos conhecimentos sobre a própria história, será relevante para toda comunidade.

Consideram-se os momentos históricos vivenciados na sociedade não aleatórios, que aconteceram desligados do tempo e do espaço, desenvolvidos em um nível local. Tais momentos 


\section{RECIMA21 - REVISTA CIENTÍFICA MULTIDISCIPLINAR ISSN 2675-6218}

HISTÓRIA E MEMÓRIA: POSSIBILIDADES DE AMPLIAÇÃO DO CONHECIMENTO NO ENSINO DE HISTÓRIA POR MEIO DE IMAGENS Paulo Augusto Tamanini, Ana Meyre de Morais

estabelecem relação com os demais níveis - regionais, nacionais e globais -, o que coloca a história local como condição indispensável que favorece a compreensão acerca de como esses processos históricos acontecem e como fortalecem identidades dos moradores que nasceram ou habitam determinada comunidade.

Como exemplificação, uma coisa que aconteceu num determinado momento numa cidade pode ter acontecido a nível de estado, no país e no mundo. Ou seja, existiu em algum momento uma ligação desse momento a conjunturas mais amplas. Os aspectos que se desenvolveram nos lugares, a história local pode tratar e a abordagem pode se dar com o uso de imagem. Como exemplifica Macedo (2017, p. 63):

[...] a História Local pode operar enquanto abordagem que privilegia um recorte espacial microlocalizado, mas que não perde seus nexos com outros tempos e espaços. Considerar a História Local enquanto abordagem quer dizer que consideramos uma metodologia, ou seja, uma forma de como o historiador trabalha em termos de seu campo de observação e das fontes que utiliza.

Destarte, ao se privilegiar de um recorte temporal e espacial, constrói-se a história local, pensando sobre as maneiras de se apropriar e limitar suas observações sobre uma determinada realidade de um povo. "A produção histórica a partir de um lugar, protege suas marcas, talvez seus moradores a consumam e retornem às pessoas na forma de um conhecimento com possibilidade de ser aceito ou contestado (MACEDO, 2017, p. 64)". No processo de construção da história, as fontes colaboram para uma melhor compreensão, e as imagens permitem a existência do diálogo, do confronto, da crítica que expressa diferentes pontos de vistas, porque nelas residem um momento da história que depois do clique foi congelado. E a sala de aula é um espaço bastante propício para se discutir sobre as formas de organização dos fatos.

No espaço escolar, o recorte local muitas vezes é pouco trabalhado. Basta fazermos uma observação rápida nos livros didáticos e observarmos a forma como os fatos históricos são organizados. É nos anos iniciais da educação escolar que acontece uma certa frequência desse recorte ser mais trabalhado. Então, nessa conjuntura, como e quando acontecem as discussões sobre a história da própria localidade nos demais níveis educacionais? Existe de fato um momento destinado para essa abordagem? Ou os acontecimentos desde a formação de um município só pode ter espaço garantido para discussão sobre sua história se acontecer na academia? Deve-se mesmo aceitar a ideia de que é somente lá que pesquisas poderiam ser feitas? Ou essa prática poderia se iniciar na própria escola para os alunos despertarem o gosto pela procura de sua própria história, fazendo valer o conhecimento histórico escolar? Segundo Bittencourt (2004, p.25):

O conhecimento histórico escolar é uma forma de saber que pressupõe um método científico no processo de transposição da ciência de referência para uma situação de ensino, permeando-se em sua reelaboração, com o conhecimento proveniente do "senso comum", de representações sociais de professores e alunos e que são redefinidos de forma dinâmica e contínua na sala de aula.

O conhecimento histórico escolar não pode ser compreendido simplesmente como um conhecimento de grandeza que se submete a um processo de simplificação para ser abordado nas salas RECIMA21 - Ciências Exatas e da Terra, Sociais, da Saúde, Humanas e Engenharia/Tecnologia 


\section{RECIMA21 - REVISTA CIENTÍFICA MULTIDISCIPLINAR ISSN 2675-6218}

HISTÓRIA E MEMÓRIA: POSSIBILIDADES DE AMPLIAÇÃO DO CONHECIMENTO NO ENSINO DE HISTÓRIA POR MEIO DE IMAGENS Paulo Augusto Tamanini, Ana Meyre de Morais

de aulas das primeiras etapas escolares. Há de se compreender a importância da participação popular no processo de construção da história. Ela não pode ser negada, induzindo estudantes que fazem parte dessa massa a cultivarem ideias que desqualificam sua história, enquanto fortalecem as ideias de que somente a história de grupos dominantes é que devem ser dignas de estudos, de registros, de atenção. Fortalecendo ainda mais o sentimento de impotência no que diz respeito a ideias de um mundo melhor.

Fernandes (1995, p. 45) destaca que determinados fatos históricos e seus respectivos personagens durante certo tempo era o que aprendíamos, pois se tratava do que constava nos livros didáticos sem constar sequer uma participação mínima do cidadão comum no cenário da História. A vida cotidiana, os grandes acontecimentos ligados aos alunos eram ignorados. Certamente essa visão da História, numa perspectiva personalista com destaque para datas, personalidades e fatos isolados de patriotismo é a visão que os estudantes abominam e tanto detestam, haja vista se tratar de algo distante do seu tempo presente, das situações experienciais de vida.

Trata-se de um passado com aspectos uniformizantes que não só exclui a participação comunitária como desconsidera o valor da coletividade ao impor valores e memórias. O autor enfatiza que a História pode ser entendida como emoção e vida, mas que é uma pena os professores não saberem desenvolver uma prática pedagógica que dê a devida importância de que História é vida, e, portanto, na escola deve existir um espaço para a história que envolve as experiências de vida de seus alunos e sua comunidade.

Assim, importa pensar em propostas que repensem como esse conhecimento histórico local está sendo produzido e como estará ganhando significado e importância no Ensino. Porque é nas pequenas e grandes localidades de uma nação que residem milhares de cidadãos e consequentemente suas histórias são iniciadas e também vivenciadas. Que se comece então por uma história que tenha a ver com a própria realidade. Vejamos a seguir algumas imagens que poderão colaborar para construção de novos conhecimentos pertinentes ao município de Baraúna-RN.

\section{AS IMAGENS E AS POSSIBILIDADES DE APRENDIZAGENS NA SALA DE AULA}

Como registros, evidências da história, as imagens fazem parte de um processo que envolve produtores e também consumidores. Seus domínios alcançam diversas áreas do saber e como detentora de poder de comunicação, seja como signo ou símbolo, chegam a despertar interesse sobre essa capacidade de comunicabilidade que possui nos comportamentos humanos.

As imagens na sala de aula devem ser tratadas com atenção, pois possuem suas distinções, possuem certas fronteiras que dizem respeito às suas características próprias. Fonseca (2009, p. 189) afirma que "as imagens constituem fontes importantíssimas para o processo de ensino e aprendizagem, pois ampliam o olhar, possibilita o desenvolvimento da observação e da crítica". Nesse sentido, deve-se pensar sobre os benefícios de se iniciar uma abordagem histórica e que essa possa apresentar uma perspectiva imagética, com o professor interagindo e problematizando imagens que dizem respeito à uma determinada realidade, contribuindo para a existência de novos conhecimentos até mesmo da própria realidade e com relevância para toda comunidade, haja vista ser "a fotografia um documento da eternidade

(MARTINS, 2008, p. 22) ". Vejamos a seguinte imagem:

RECIMA21 - Ciências Exatas e da Terra, Sociais, da Saúde, Humanas e Engenharia/Tecnologia 


\section{RECIMA21 - REVISTA CIENTÍFICA MULTIDISCIPLINAR ISSN 2675-6218}

HISTÓRIA E MEMÓRIA: POSSIBILIDADES DE AMPLIAÇÃO DO CONHECIMENTO NO ENSINO DE HISTÓRIA POR MEIO DE IMAGENS Paulo Augusto Tamanini, Ana Meyre de Morais

IMAGEM 1: Escola Estadual João de Abreu

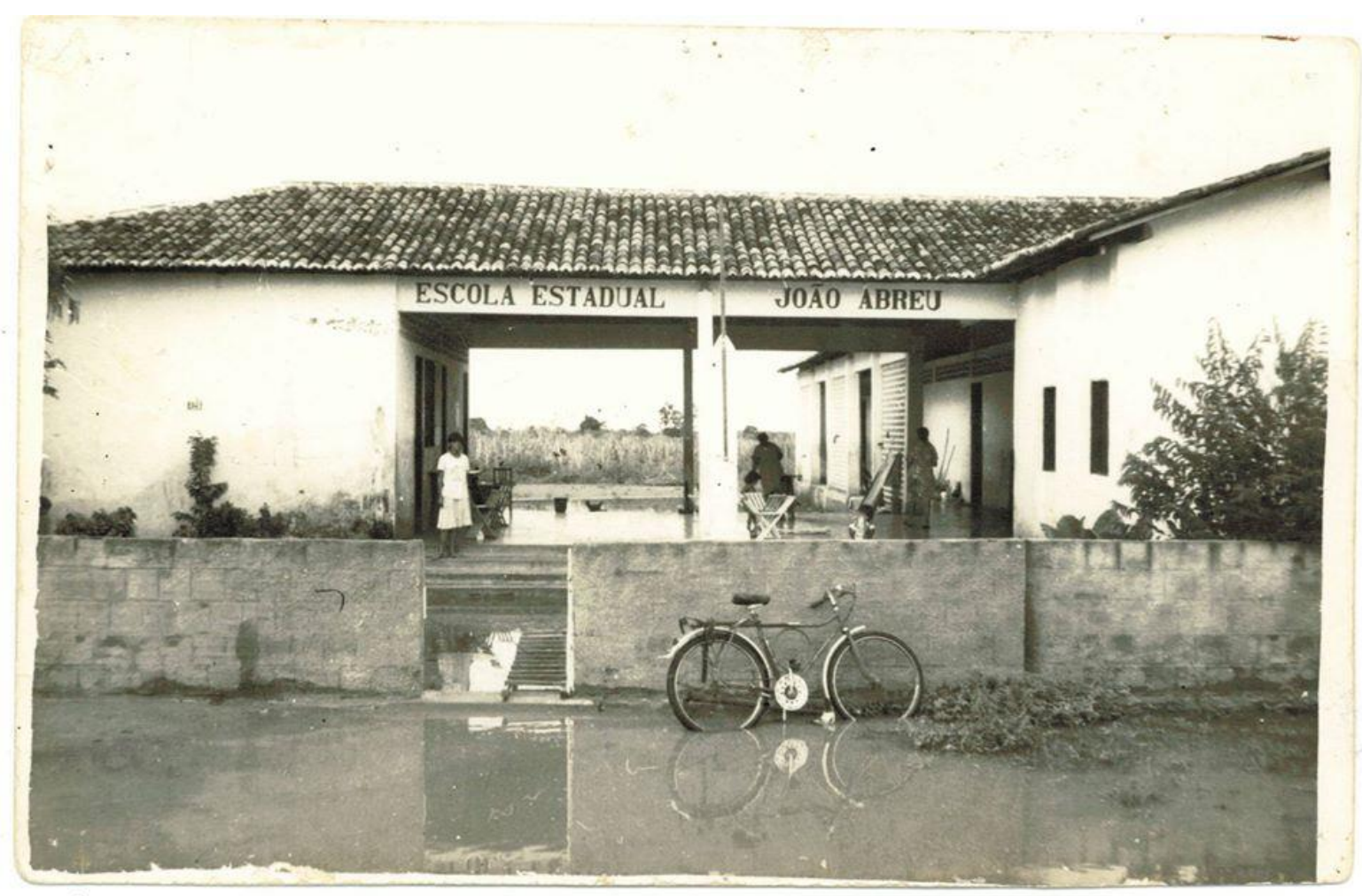

FONTE: Barboza (2017, p. 32).

A imagem acima trata da Escola Estadual João de Abreu de Ensino Fundamental e Médio, localizada no munícipio de Baraúna- RN. Em preto e branco, a fotografia mostra uma realidade de um contexto difícil de alagamento, enfrentado em períodos chuvosos que se estendeu até pouco tempo. A estrutura mostrada pela fotografia se comparada com fotografias atuais, irão dar conta de que houve "poucas" mudanças. Porém, quando apresentada a moradores, alunos ou funcionários da época, detalhes serão evidenciados, como por exemplo destacou Elise $(2020)^{1}$, ex-aluna e ex-funcionária da escola:

Vixe, é a Escola João de Abreu, ela começou em 1965, na época era chamada de Escolas Reunidas João de Abreu... ela tinha uma cerquinha na frente, desses paus de cerraria, aquelas tabuinhas, quando ela foi feita, depois foi que fizeram esse muro. Eram apenas três salas... Antonieta foi diretora lá, dona Maria Barros foi também... Dona Maria Barros também trabalhou na Escola Cunha da Mota. Ela tinha um prédio ali na rua da frente, onde ela ensinava, era o Educandário Cortez Pereira, aí ela mudou... eu acho que ela deve ter recebido alguma ajuda do povo de Mossoró porque aqui ainda não era cidade $e$ ela tinha muito contato com pessoas influentes, tinha muito aluno, era educação integrada $[\ldots]$.

A inauguração da escola ocorreu em 11 de outubro de 1965, no governo de Aluízio Alves. A década de 60 na história do Estado do Rio Grande do Norte foi marcada pelo aparecimento de vários movimentos e campanhas que intencionavam o desenvolvimento de projetos educacionais, como informa

\footnotetext{
1 Nome fictício dado a ex-funcionária.

RECIMA21 - Ciências Exatas e da Terra, Sociais, da Saúde, Humanas e Engenharia/Tecnologia
} 


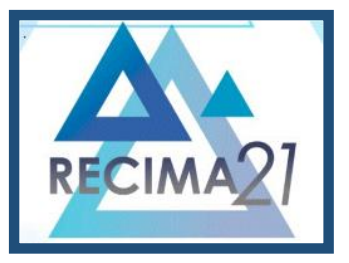

\section{RECIMA21 - REVISTA CIENTÍFICA MULTIDISCIPLINAR ISSN 2675-6218}

HISTÓRIA E MEMÓRIA: POSSIBILIDADES DE AMPLIAÇÃO DO CONHECIMENTO NO ENSINO DE HISTÓRIA POR MEIO DE IMAGENS Paulo Augusto Tamanini, Ana Meyre de Morais

Goés (1980), mas isso é um parêntese aberto que poderá suscitar discussões sobre qual o contexto deuse o início da sua história de construção que tudo tem a ver com a história do munícipio.

Retomando a discussão, as imagens de épocas passadas trazem consigo evidências de um tempo que se escoou, não podem ser analisadas como simulacros sem vida, porque elas são resultado de propósitos estabelecidos, de formas diferenciadas de olhar uma realidade, de olhar o mundo. Semelhante a outras fontes, as imagens trazem para o presente lacunas e silêncios que necessitam serem discutidos, interpretados, não somente para se ampliar o olhar sobre leitura de imagens, mas também de favorecer a aquisição de habilidades e atitudes de investigação, indagação sobre a própria história.

Em Memórias que pude contar, de Ivanilde Barboza (2017, p. 32), autora e professora que atuou nesse contexto escolar, ao narrar suas memórias para a família, destaca o período em que começou a trabalhar na referida escola, reforçando o nome Escolas Reunidas João de Abreu, e ainda que a escola recebeu o nome do seu avô, João Francisco de Abreu.

Mesmo a narrativa da professora Ivanilde Barboza (2017) sendo feita de forma sucinta, nas três décadas de trabalho na área educacional é possível encontrar nomes de pessoas que detinham o poder de influência política, cursos realizados para capacitar professores, além de outros vestígios que estabelecem ligação com outro contexto escolar. Sem falar que ela também dá ênfase a filhos e à neta que atualmente trabalham na referida escola. Reforçando assim, alguns pontos apresentados por Elise (2020) anteriormente.

Sobre a ligação de um contexto escolar com outro, a professora Ivanilde Barboza (2017) informa ter feito parte do contexto da Escola Cunha da Mota por sete anos, uma das primeiras escolas do munícipio, fundada no ano de 1947, mas que tempos mais tarde no ano de 1986 teve seu nome mudado para Escola Municipal de $1^{\circ}$ Grau Prof. Amauri Ribeiro da Silva. Contudo, observemos que na fala de Elise (2020) existe uma riqueza histórica que poderá ser evidenciada a partir de uma imagem que Ihes foi apresentada. Ela cita o nome da Escola Cunha da Mota e dá destaque para o nome de Maria Barros como pessoa atuante em ambos os contextos, assumindo cargos de direção. Então, quem mais fez parte desses dois contextos escolares? Vejamos outra imagem: 


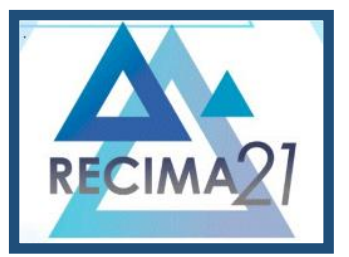

\section{RECIMA21 - REVISTA CIENTÍFICA MULTIDISCIPLINAR ISSN 2675-6218}

HISTÓRIA E MEMÓRIA: POSSIBILIDADES DE AMPLIAÇÃO DO CONHECIMENTO NO ENSINO DE HISTÓRIA POR MEIO DE IMAGENS Paulo Augusto Tamanini, Ana Meyre de Morais

IMAGEM 2: Escola Municipal Manoel de Barros²

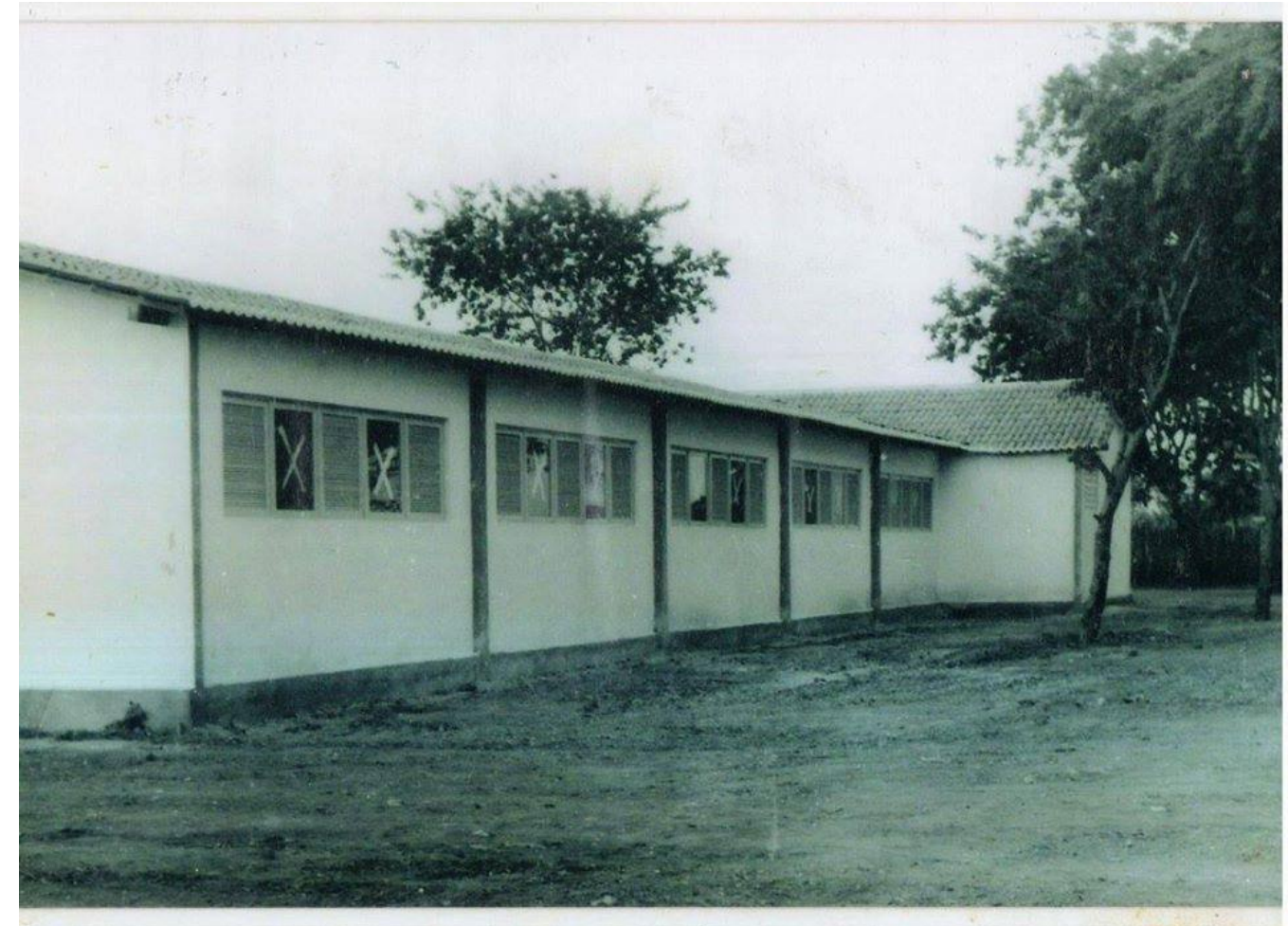

FONTE: Acervo da escola

A imagem acima mostra outro espaço escolar do município, com características de uma arquitetura tradicional, num espaço que demonstra integrar homem, espaço e natureza. Mesmo em preto e branco, o ângulo escolhido para enquadrar a construção não deixou negligenciar o espaço amplo escolhido para sua construção, nem tão pouco as árvores ao seu redor, elementos fundamentais para se iniciar uma discussão sobre a história de um povo. Conhecida como a primeira instituição de responsabilidade municipal, inicialmente chamou-se Ginásio Municipal Anexo Baraúna e era vinculada à escola anterior - a Escola Estadual João de Abreu. Esse modo de funcionamento foi do ano de 1973 até 1977.

Foi por meio do Decreto no 95/7833, Prefeitura de Mossoró, que a escola teve suas atividades iniciadas ainda no mesmo ano de 1978 e sua Portaria de autorização ํㅜ 110/86 the credencia e um reconhecimento de trabalho se concretiza. A escola recebe o nome de um dos primeiros moradores, Manoel Barros de Oliveira, como forma de reconhecimento pelo trabalho dedicado ao desenvolvimento da educação no município, cujas lutas junto às autoridades foram constantes. Sua filha, Maria Barros Feitosa, foi a primeira professora quando ainda o município era um vilarejo. Foi na gestão de João Newton da Escócia, prefeito de Mossoró na época, que seu Ato de criação foi assinado. Mas acontece que as histórias das escolas são pouco conhecidas, para se chegar nelas, não seria pertinente conhecer a história do

2 Disponível em: https://www.facebook.com/photo.php?fbid=102316676790765\&set=pb.100010372982259.2207520000..\&type=3\&theater. Acesso em: 08 de abril de 2020.

${ }^{3}$ Disponível em: << http://mbescola.blogspot.com/p/institucional.html >> Acesso em 24/04/2020. RECIMA21 - Ciências Exatas e da Terra, Sociais, da Saúde, Humanas e Engenharia/Tecnologia 


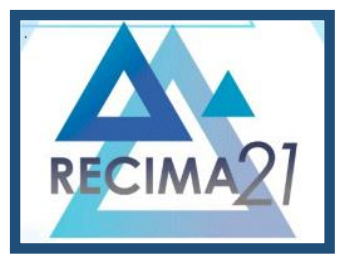

\section{RECIMA21 - REVISTA CIENTÍFICA MULTIDISCIPLINAR ISSN 2675-6218}

HISTÓRIA E MEMÓRIA: POSSIBILIDADES DE AMPLIAÇÃO DO CONHECIMENTO NO ENSINO DE HISTÓRIA POR MEIO DE IMAGENS Paulo Augusto Tamanini, Ana Meyre de Morais

município? E com isso dar início a novas discussões em sala de aula e assim potencializar o ensino de História?

Essa imagem também foi apenas mostrada a Leocina ${ }^{4}(2020)$ ex-funcionária aposentada, que se pronunciou:

Aqui é o Ginásio, hoje conhecido como Manoel de Barros, essa escola começou primeiramente por Mossoró... essa área onde foi construída a escola se chamava já na época de Horto Florestal. Está vendo essas árvores aqui? Era só planta nesse terreno... tinha muitas árvores grandes...era por isso que todo mundo chamava de Horto Florestal, era por causa das plantas. Eu cheguei ainda a conhecer seu Manoel Barros, ele era o pai da primeira professora daqui. Ela escreveu muita coisa daqui, só que é em poesia [...].

O passado que fora congelado a partir de um clique parece informar vestígios sobre a história até mesmo da rua em que se encontra a própria escola. Não seria então importante abordar essas e outras imagens em sala de aula para se discutir sobre a história da escola e até do próprio município e de seus moradores?

Nos livros: "Baraúna sua gente sua história", de Santos Júnior (1999) e "Terras Potiguares", de Morais (2007), ambos apresentam informações históricas pertinentes ao município supracitado, principalmente o primeiro livro que apresenta situações narradas por pessoas que foram protagonistas do início dessa história baraunense. Há atores dessa história ainda vivos e que podem, por sinal, até enriquecer com detalhes que na época não foram ou pouco foram explorados. Mas como iniciar essa abordagem partindo de imagens? Apresentá-las e problematizá-las em sala de aula pode ser os primeiros passos a serem dados. Apenas uma parte da história desse município foi pelos autores apresentada, as imagens relacionadas a essa história guardam informações de momentos posteriores. Mas nos debrucemos um pouco na história do município para melhor compreender como essa abordagem da história pode ser feita numa perspectiva imagética, com bons resultados em sala de aula.

O Vilarejo ao qual os moradores salvaguardam como sendo chamado inicialmente de "Rancho do Sabiá", pela justificativa de que a localidade era uma área que servia de acolhida para tropeiros que percorriam o trajeto do Ceará para Mossoró, ao longo de sua história ${ }^{5}$ teve seu nome mudado para Baraúna. Nesse processo de mudança, já envolve muitas outras histórias que discutem a razão do nome Baraúna, pois inexiste consenso entre elas as versões.

Segundo Santos Júnior (1999, p. 3) o povoamento deu-se nos anos de 1930 a 1935 com a chegada do agricultor João Batista Dantas, primeiro morador. Em seguida chegaram outros habitantes que tinham por nome: Guilherme Freire, Maria Fulô, Pedro André, José Abreu, Severino Tavares, Serra Negra, Amâncio Poeira, e Manoel Perninha. Esse vilarejo foi descrito como região de difícil acesso, devido ser uma floresta espessa, com uma falta de água que se mostrou ser outro fator que inviabilizava a permanência de moradores, embora houvesse a riqueza abundante em vegetais e uma grande diversidade de animais. Nessa história destaca-se a proeza e persistência do primeiro morador - João Batista Dantas

\footnotetext{
4 Nome fictício dado a ex-funcionária da Escola Manoel de Barros.

5 Disponível em: <<https://barauna.rn.gov.br/index.php/pt/historia>> Acesso em 19/04/2020.
} 


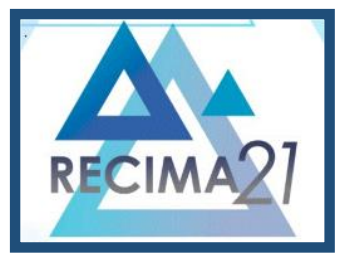

\section{RECIMA21 - REVISTA CIENTÍFICA MULTIDISCIPLINAR ISSN 2675-6218}

HISTÓRIA E MEMÓRIA: POSSIBILIDADES DE AMPLIAÇÃO DO CONHECIMENTO NO ENSINO DE HISTÓRIA POR MEIO DE IMAGENS Paulo Augusto Tamanini, Ana Meyre de Morais

- que observou ser exatamente a escassez da água um dos fatores decisivos para a não permissão de habitação de moradores. Vejamos a fotografia conhecida na cidade como sendo a desse protagonista:

IMAGEM 3: "Primeiro morador do município"

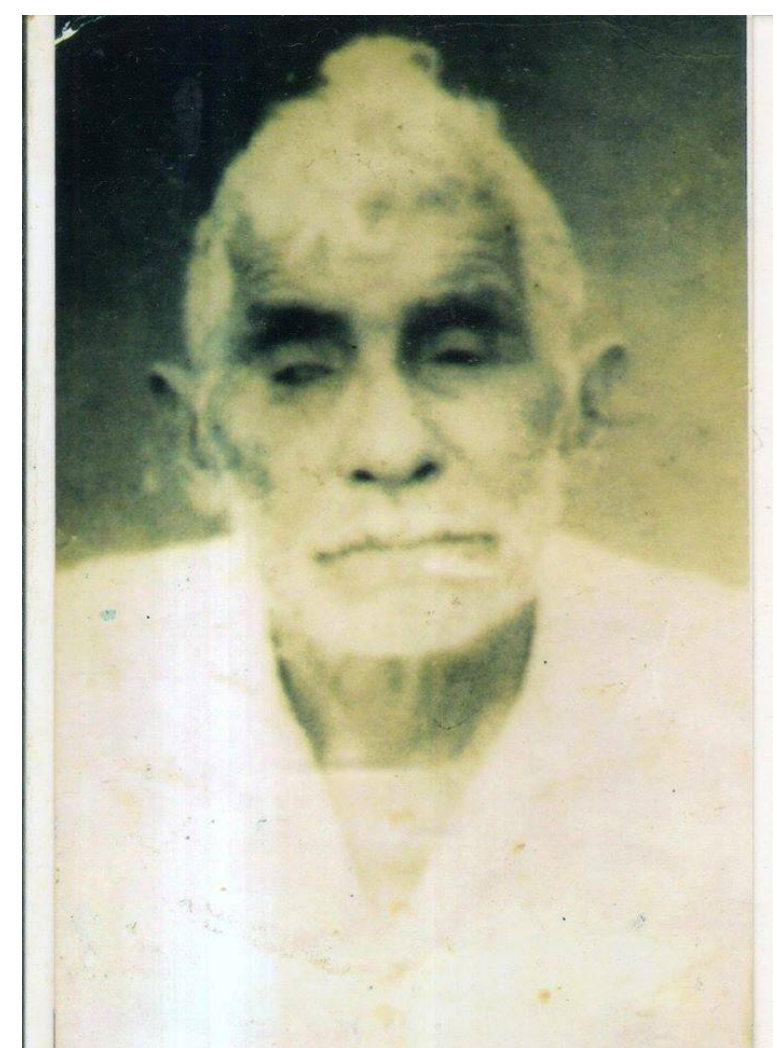

Fonte: Santos Júnior (1999, p.85).

Ainda conforme o autor, o primeiro morador diante dessa situação difícil, decidiu ir até o palácio do governador, em Natal, capital do Estado do Rio Grande do Norte, solicitar às autoridades um Poço de água. Na época "nem se podia falar" em formas rápidas e práticas de deslocamentos, essas coisas eram distantes da realidade em que ele se encontrava. Desprovido desses fatores, restou-lhes tão somente a força de vontade, a determinação de ir mesmo a pé. Depois de ter percorrido cerca de 300 km para chegar ao destino planejado, ainda que seus pés mostrassem entumecidos, seus argumentos já estavam conscientemente preparados para falar com o interventor da época sobre o seu pedido. A solicitação de perfuração do Poço veio favorecer a área, tornando-a habitável.

Os moradores que já se encontravam arranchados, Manoel Barros de Oliveira, Leandro Anselmo de Medeiros, Antônio Alves e Francisco Tintino, permaneceram e deram início a outra parte da história. Dentre esses nomes dos primeiros moradores, encontra-se não somente a história de um simples povoado, mas também a história dos que protagonizaram a história do processo educacional do município.

\footnotetext{
6 João Batista Dantas, falecido em Mossoró no ano de 1975, segundo conta seu filho Geraldo Carlos Batista na obra de Santos Júnior (1999, p. 65).

RECIMA21 - Ciências Exatas e da Terra, Sociais, da Saúde, Humanas e Engenharia/Tecnologia
} 


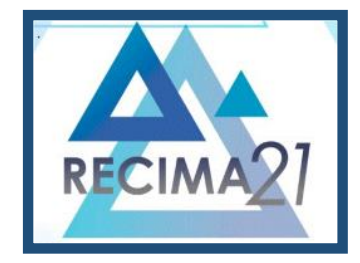

\section{RECIMA21 - REVISTA CIENTÍFICA MULTIDISCIPLINAR ISSN 2675-6218}

HISTÓRIA E MEMÓRIA: POSSIBILIDADES DE AMPLIAÇÃO DO CONHECIMENTO NO ENSINO DE HISTÓRIA POR MEIO DE IMAGENS Paulo Augusto Tamanini, Ana Meyre de Morais

De acordo com Morais (2007, p. 37), localizado no Estado do Rio Grande do Norte, Baraúna foi um povoado pertencente a Mossoró que teve sua ascensão criada a Distrito de Baraúna através da Lei Municipal ํo. 889 de 17 de novembro de 1953. Para se elevar a categoria de município, um plebiscito fora iniciado e teve como decisão o desmembramento da cidade de Mossoró. Sua emancipação política é respaldada pela Lei oㅜ 5.107, em 15 de dezembro de 1981, validada pelo Governador do Estado Dr. Lavoisier Maia Sobrinho.

Os estudos de Albano (2011) e Cruz (2015) que discutem sobre o processo de Globalização da agricultura e movimentos na estrutura e política fundiária que envolve o munícipio contribuem para uma possível contextualização, já que atualmente o município é conhecido como Terra da fruticultura irrigada. Se antes a escassez de água dificultou o seu povoamento, as suas águas subterrâneas, solos férteis e etc., atraíram investidores que deram início a sua história de evolução.

Mas será que os alunos conhecem a fundo a sua própria história? Os lugares não existiram desde sempre, ao longo do tempo foram se constituindo, e as imagens guardam informações a partir de recortes da realidade que foram feitos e permitem conhecer aspectos sobre o passado. Ao se fazer o recorte local, entra em cena a história educacional.

Na obra de Santos Júnior (1999, p. 7), Maria Barros Feitosa relembra a forma como o vilarejo aos poucos foi sendo formado: "A mata cobria quase tudo, no fundo de nossos quintais existia grande quantidade de madeira de boa qualidade, quando chegava um novo habitante tinha de desbravar toda a mata ao redor para assentar sua residência".

Podemos perceber que o sobrenome "Barros" se associa ao sobrenome de um dos primeiros moradores, a filha de Manoel Barros de Oliveira, lembram? De acordo com Santos Júnior (1999), quando chegaram no vilarejo, Maria Barros Feitosa, nascida em São José de Campestre-RN, em 28 de maio de 1914, foi quem iniciou o processo educacional dos moradores, ensinando as primeiras letras numa espécie de casebre e as suas atividades se iniciaram no dia 04 de maio de 1938. Vejamos a fotografia da professora: 


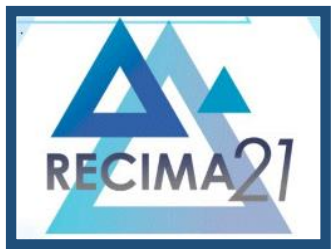

\section{RECIMA21 - REVISTA CIENTÍFICA MULTIDISCIPLINAR ISSN 2675-6218}

HISTÓRIA E MEMÓRIA: POSSIBILIDADES DE AMPLIAÇÃO DO CONHECIMENTO NO ENSINO DE HISTÓRIA POR MEIO DE IMAGENS Paulo Augusto Tamanini, Ana Meyre de Morais

IMAGEM 4: "Primeira Professora, Maria Barros Feitosa"”

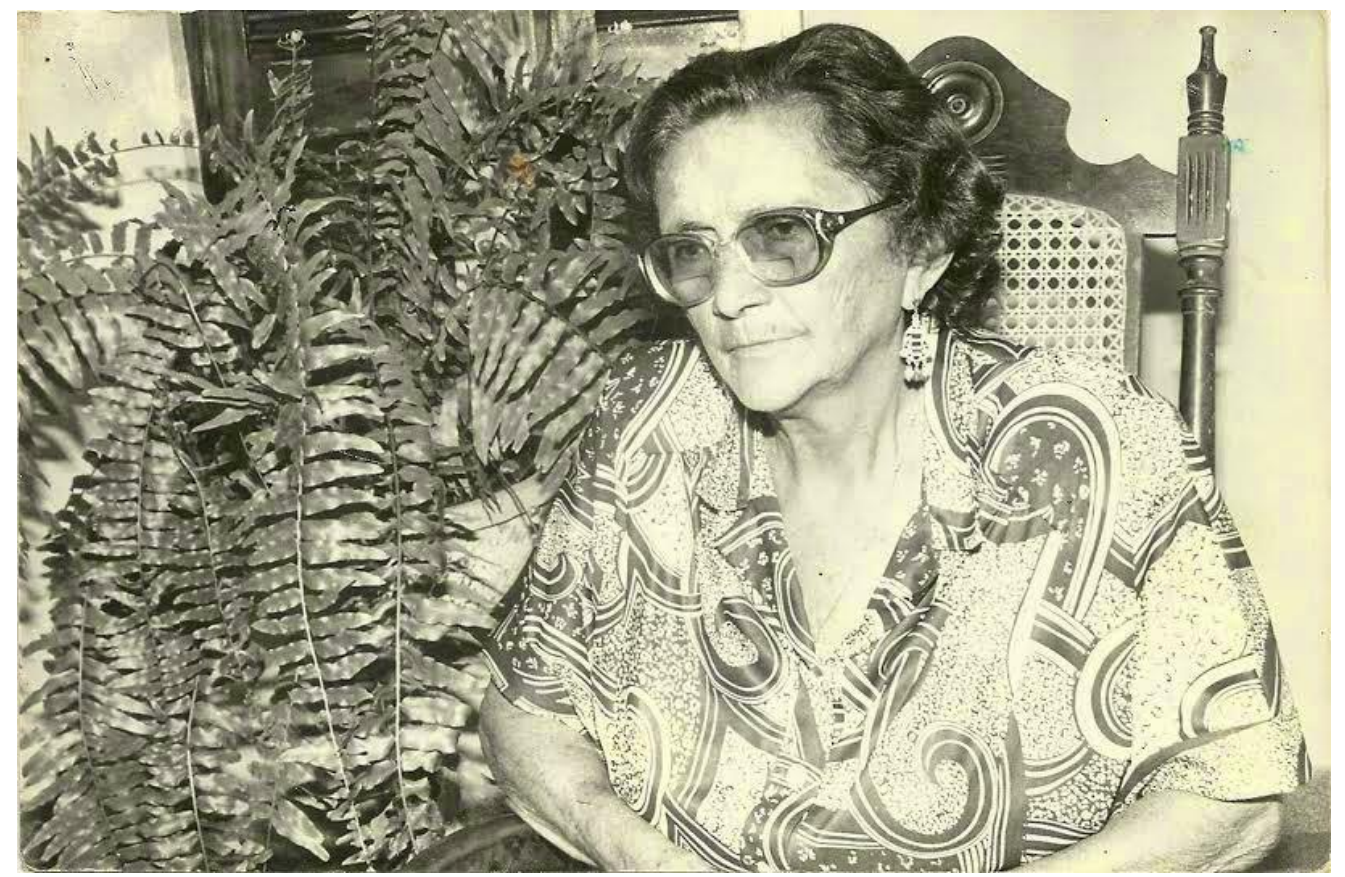

Fonte: Blog Alerta Baraúna.

A bandeira que fora erguida pela professora por educação para os moradores na época, foi defendida ao longo de toda a sua história. Sobre esse momento, na obra de Santos Júnior (1999, p. 61) ela se pronuncia dizendo que:

Apenas tinha aqui 06 moradores, mas ao mesmo tempo chegava gente de todos os Estados para morar. Era como os sem terras. Só que aqui não tinha dono, cada família tirava um pedaço de mata para trabalhar, só com a ajuda de Deus. Foi quando eu procurei saber se este povo sabia ler. Era todos analfabetos e eu tive pena. Disse para o meu esposo, eu vou ensinar esse povo a ler. E comecei ensinando criança pela manhã e adultos a noite [...]. Ensinava com lamparina de querosene, as vezes acabava e não tinha onde comprar, eu fazia vela de cera de abelha e dava minha aula com amor.

Na fala de Elise (2020), ao se posicionar sobre o contexto da primeira imagem, há destaque para a professora Maria Barros. Então, podemos perceber a forte atuação ${ }^{8}$ da professora no município. Já Leocina (2020) relembra que a professora era poetisa, e muita coisa que ela escreveu sobre a cidade foi em forma de poesia, e isso nos fez lembrar do que pontuou Fonseca (2009, p. 183):

A história não é algo abandonado, parado na beira de uma estrada ou uma estação. A história é movimento, transformação, contradição, diferença. E também poesia.

A linguagem poética expressa outra forma de ver, escrever e expressar sentimentos sobre variados temas, questões, fatos, sujeitos e práticas sociais e culturais. Seduz, age sobre nós, intervém, nos provoca. Assim, pode fornecer pistas para alargar a compreensão dos temas históricos com beleza e sensibilidade.

\footnotetext{
7 Disponível em: http://alertabarauna.blogspot.com/2014/05/nossa-professora-dona-maria-barros.html Acesso em: 10 abr. 2020.

${ }^{8} \mathrm{Na}$ obra de Santos Júnior (1999, p. 62), o filho do primeiro morador em seu relato confirma a chegada da família Barros no ano de 1937 e que Maria Barros Feitosa se dispôs a ensinar.
}

RECIMA21 - Ciências Exatas e da Terra, Sociais, da Saúde, Humanas e Engenharia/Tecnologia 


\section{RECIMA21 - REVISTA CIENTÍFICA MULTIDISCIPLINAR ISSN 2675-6218}

HISTÓRIA E MEMÓRIA: POSSIBILIDADES DE AMPLIAÇÃO DO CONHECIMENTO NO ENSINO DE HISTÓRIA POR MEIO DE IMAGENS Paulo Augusto Tamanini, Ana Meyre de Morais

As narrativas suscitadas pelas imagens deram conta até mesmo de outros contextos municipais escolares. No ano de 1963 a professora foi designada como diretora da Escola Cunha da Mota. Mas é no Educandário Gov. Cortez Pereira, que seu trabalho tem uma maior relevância, no ano 2000 passou-se a se chamar Escola Municipal de 1ํ-Grau Professora Maria Barros Feitosa, em sua homenagem. Sua presença marcante não se restringe somente aos contextos escolares da cidade, mas a formação da sociedade em que estava inserida. No ano de 2007 ela veio a óbito, deixando um grande legado. A escola não poderia desenvolver um trabalho com seus alunos, fazer uma busca de imagens da época, buscar informações, se aprofundar nos detalhes, registrar e compartilhar com toda comunidade? Claro que é possível.

A proposta de iniciar uma discussão sobre a história da escola em sala de aula, fazendo uso de imagens da própria instituição pode ser considerada uma oportunidade também de valorização de um recorte local, e vice-versa. A história de uma escola não pode se resumir somente a informar sobre a quantidade de alunos matriculados e seus respectivos diretores passados e atuais, mas ouvir as vozes daqueles que podem dizer como tudo começou. Sobre as formas de lutas que foram empreendidas para fazer valer a sua construção na cidade, quem foram sujeitos protagonistas deste momento, quem foram seus primeiros professores e alunos, e o que eles dizem sobre essa época.

Numa busca mais profunda, é interessante buscar as metodologias usadas nas salas de aula para fazerem os alunos avançarem. Nesse cenário de pouca informação, a história da escola acaba sendo "desconhecida" ou "pouco explorada", assim como também a história local, o que consequentemente pode gerar uma certa "carência" do conhecimento da própria história que certamente contribuiria para a existência do reconhecimento dos sujeitos históricos que pertencem a um determinado lugar. Enfim, parte dessa história se encontra guardada na memória dos seus moradores, que a fotografia eternizou, e a existência dessa relação entre história e fotografia mediante discussão em sala de aula pode fortalecer o ensino aprendizagem porque se encontra à espera de serem relembradas, discutidas, refletidas e registradas.

\section{CONSIDERAÇÕES FINAIS}

Imagens apresentadas na sala de aula para serem usadas como ferramenta pedagógica são recursos eficazes para o ensino e aprendizagem. Trata-se de uma proposta que desafia professores e alunos a trabalharem com a pesquisa, com a capacidade de refletir por meio de imagens do próprio contexto. Faz-se necessário contornar a prática corrente de ver a imagem apenas como uma ferramenta meramente ilustrativa de textos verbais, focando apenas na responsabilidade de produzir bons leitores de textos verbais e acaba esquecendo de que as imagens também são textos, só que visuais.

Entretanto acontece que o visual é ignorado, sendo que sua função vai muito além da questão estética, ilustrativa em painéis, cartazes e outras coisas mais. A imagem é portadora de conhecimento, e recurso estratégico para a prática pedagógica. Ela é produzida por sujeitos em determinado tempo e 


\section{RECIMA21 - REVISTA CIENTÍFICA MULTIDISCIPLINAR ISSN 2675-6218}

HISTÓRIA E MEMÓRIA: POSSIBILIDADES DE AMPLIAÇÃO DO CONHECIMENTO NO ENSINO DE HISTÓRIA POR MEIO DE IMAGENS Paulo Augusto Tamanini, Ana Meyre de Morais

espaço, guarda marcas de quem as produziu e por essa razão é importante que haja um bom relacionamento entre leitor e imagem. É preciso refletir que, ao se analisar uma imagem, existe essa relação, mas que não se dá de forma rápida, automática. Nessa relação, existe o sujeito que está a observar e a imagem que se dispõe a dialogar, existe um processo de investida de sentido que se faz importante passar por um processo reflexivo antes de ser usada em sala de aula.

Desse modo, as imagens que tratam de contextos escolares apresentam histórias que não podem ser ignoradas, uma vez que a própria escola possui sua história. Ainda que muitas vezes seja ignorada, ela se encontra intimamente ligada até mesmo com à história local. Descredenciar esse conhecimento é o mesmo que ignorar que existe uma certa fragilidade no que diz respeito ao conhecimento histórico. E se assim for, esse aprendizado poderá ser descrito como deficiente, insuficiente, ou seja, alunos encerram o ensino fundamental e médio, ingressam nas faculdades sem que o currículo escolar tenha possibilitado a construção de identificação do seu próprio passado.

É preciso problematizar imagens de forma que elas possam mostrar seus efeitos de sentido, nesse processo de construção de identificação, e isso requer uma certa atenção no uso de imagens no ensino, precisa existir melhor aproveitamento da imagem em sala de aula e que esse possa ser interativo, com suficiente capacidade para despertar o interesse pela relevância do conhecimento da própria história, fortalecendo e dinamizando assim o ensino de História.

Deste modo, a História sozinha não faz as descobertas, estas acontecem porque alguém dá a ela atenção, porque interessam as coisas que aconteceram no passado. A partir disso, busca-se no presente uma melhor compreensão do momento atual, e ainda com expectativas para traçar novos rumos. Observemos então que as imagens quando apresentadas às pessoas que fizeram parte dos contextos de outrora trouxeram o passado para o agora: é como se aquele instante que fora congelado pela imagem tivesse sido vivenciado recentemente, contado com uma riqueza de detalhes suscitados pelas imagens que acabaram estabelecendo relação direta com a história de seus moradores e da cidade. Logo, os resultados demonstraram que as imagens guardam informações não somente sobre a história da própria escola, mas também da história local com potencial para favorecer o Ensino de História no que diz respeito à construção da identidade dos alunos como ser histórico, para exercerem plenamente sua cidadania.

\section{REFERÊNCIAS}

ALBANO, Gleydson Pinheiro. Globalização da agricultura: uma análise comparativa entre duas cidades com fruticultura irrigada para exportação no RN, Ipanguaçu e Baraúna. Recife: Programa de PósGraduação em Geografia, 2011. Disponível em: https://docplayer.com.br/30844136-Gleydson-pinheiroalbano.html. Acesso em: 12 maio 2020.

BARROS, José D’Assunção. História, Espaço e Tempo: interações necessárias. Revista Varia Historia, Belo Horizonte, v. 22, n. 36, p. 460-476, jul./dez. 2006.

BARBOZA, Francisca Ivanilde. Memórias que pude contar. Mossoró-RN: Gráfica Creatores Mater, 2017. 


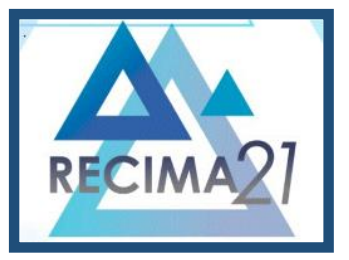

\section{RECIMA21 - REVISTA CIENTÍFICA MULTIDISCIPLINAR ISSN 2675-6218}

HISTÓRIA E MEMÓRIA: POSSIBILIDADES DE AMPLIAÇÃO DO CONHECIMENTO NO ENSINO DE HISTÓRIA POR MEIO DE IMAGENS Paulo Augusto Tamanini, Ana Meyre de Morais

BITTENCOURT, Circe M. F. Capitalismo e cidadania nas atuais propostas curriculares de História. In.: BITTENCOURT, Circe M. F. (Org.). O saber escolar em sala de aula. São Paulo: Contexto, 1998.

CRUZ, Rogério Pires. Concentração da propriedade da terra e política fundiária na microrregião homogênea de Mossoró: o caso de Baraúna (RN), 1962/2006. Revista Interface, jul./dez. 2015.

ELISE. Ex-funcionária da Escola Estadual João de Abreu. Atividade realizada em 18 de abril de 2020. Acervo dos autores.

FAGUNDES, José Evangelista; ANDRADE, Joel Carlos de Souza. Pensando a história: noções introdutórias. In.: ALVEAL, Carmem Margarida Oliveira; FAGUNDES, José Evangelista; ROCHA, Raimundo Nonato Araújo (Org.). Reflexões sobre história local e produção de material didático [recurso eletrônico]. Natal: EDUFRN, 2017.

FERNANDES, José Ricardo Oriá. Um lugar na escola para a História Local. Ensino em Re-Vista, Uberlândia, v. 4, n. 1, jan./dez. 1995.

FONSECA, Selva Guimarães. Fazer e ensinar História. Belo Horizonte: Dimensão, 2009.

LEOCINA. Ex-funcionária da Escola Municipal de 1ํㅡㅁ Gau Manoel de Barros. Atividade realizada em 18 de abril de 2020. Acervo dos autores.

GÓES, Moacyr de. De Pé no Chão Também se Aprende a Ler (1961-64). Rio de Janeiro-RJ: Ed. Civilização brasileira, 1980. Coleção Educação e Transformação, v. 3.

MACEDO, Helder Alexandre Medeiros de. De como se constrói uma história local: aspectos da produção e da utilização no ensino de história. In.: ALVEAL, Carmem Margarida Oliveira; FAGUNDES, José Evangelista; ROCHA, Raimundo Nonato Araújo (Org.). Reflexões sobre história local e produção de material didático [recurso eletrônico]. Natal: EDUFRN, 2017.

MORAIS, Ana Meyre de; TAMANINI, Paulo Augusto. Leituras de imagens de cunho violento no ensino de História: do estupor à aprendizagem. In.: TAMANINI, Paulo Augusto (Org.). História Ensinada: uma prosopografia do Ensino de História, no Brasil. Curitiba: CRV, 2020.

MORAIS, Marcus Cesar Cavalcanti de. Terras Potiguares. 3. ed. Natal-RN: Editora Foco, 2007.

MARTINS, José de Souza. Sociologia da fotografia e da imagem. São Paulo: Contexto, 2008.

SANTOS JÚNIOR, Valdeci dos. Baraúna: sua gente, sua história. Baraúna: [s.n.],1999. 